\title{
Erratum to: The Quantization of Gravity
}

\section{Erratum to: C. Gerhardt, The Quantization of Gravity, Fundamental Theories of Physics 194, https://doi.org/10.1007/978-3-319-77371-1}

The original version of the book was inadvertently published without incorporating the belated corrections of minor typographical errors from author, which have to be now incorporated throughout. The erratum book has been updated with the changes.

The updated online version of this book can be found at https://doi.org/10.1007/978-3-319-77371-1_1

https://doi.org/10.1007/978-3-319-77371-1_2

https://doi.org/10.1007/978-3-319-77371-1_5

https://doi.org/10.1007/978-3-319-77371-1_6

https://doi.org/10.1007/978-3-319-77371-1_7

https://doi.org/10.1007/978-3-319-77371-1 